\title{
Simulation of low clouds in the Southeast Pacific by the NCEP GFS: sensitivity to vertical mixing
}

\author{
R. Sun ${ }^{1}$, S. Moorthi ${ }^{2}$, H. Xiao ${ }^{3}$, and C. R. Mechoso ${ }^{3}$ \\ ${ }^{1}$ UCAR/Environmental Modeling Center/NCEP/NOAA, Rm 209, 5200 Auth Rd., Camp Springs, MD, 20746, USA \\ ${ }^{2}$ Environmental Modeling Center/NCEP/NOAA, Rm 209, 5200 Auth Rd., Camp Springs, MD, 20746, USA \\ ${ }^{3}$ Department of Atmospheric and Oceanic Sciences University of California, Los Angeles, Los Angeles, California, USA
}

Received: 22 July 2010 - Published in Atmos. Chem. Phys. Discuss.: 4 August 2010

Revised: 22 November 2010 - Accepted: 15 December 2010 - Published: 23 December 2010

\begin{abstract}
The NCEP Global Forecast System (GFS) model has an important systematic error shared by many other models: stratocumuli are missed over the subtropical eastern oceans. It is shown that this error can be alleviated in the GFS by introducing a consideration of the low-level inversion and making two modifications in the model's representation of vertical mixing. The modifications consist of (a) the elimination of background vertical diffusion above the inversion and (b) the incorporation of a stability parameter based on the cloud-top entrainment instability (CTEI) criterion, which limits the strength of shallow convective mixing across the inversion. A control simulation and three experiments are performed in order to examine both the individual and combined effects of modifications on the generation of the stratocumulus clouds. Individually, both modifications result in enhanced cloudiness in the Southeast Pacific (SEP) region, although the cloudiness is still low compared to the ISCCP climatology. If the modifications are applied together, however, the total cloudiness produced in the southeast Pacific has realistic values. This nonlinearity arises as the effects of both modifications reinforce each other in reducing the leakage of moisture across the inversion. Increased moisture trapped below the inversion than in the control run without modifications leads to an increase in cloud amount and cloud-top radiative cooling. Then a positive feedback due to enhanced turbulent mixing in the planetary boundary layer by cloud-top radiative cooling leads to and maintains the stratocumulus cover. Although the amount of total cloudiness obtained with both modifications has realistic values, the relative contributions of low, middle, and high layers tend to
\end{abstract}



Correspondence to: R. Sun (ruiyu.sun@noaa.gov) differ from the observations. These results demonstrate that it is possible to simulate realistic marine boundary clouds in large-scale models by implementing direct and physically based improvements in the model parameterizations.

\section{Introduction}

The climatology of the tropical and subtropical Pacific Ocean south of the Equator is characterized by large east-west gradients in sea surface temperature (SST), with values increasing from $\sim 20^{\circ} \mathrm{C}$ along the South American coast to $\sim 29^{\circ} \mathrm{C}$ in the Western Pacific warm pool. Going west up the SST gradient, the dominant cloud type changes from stratocumulus with high coverage near the coast to shallow cumulus with much lower coverage over the central Pacific. This evolution of cloud regime occurs in the descending branch of the atmospheric Hadley-Walker circulation, with trade winds along the surface, and a trade wind inversion in the lower troposphere that elevates and weakens along the direction of the SST gradient. In this broad sense, the Southeast Pacific (SEP) climate is a tightly coupled system, in which poorly understood interactions develop among clouds, marine boundary layer (MBL) processes, upper ocean dynamics and thermodynamics, coastal currents and upwelling, largescale subsidence, regional diurnal circulations, and aerosol effects.

Interactions between the South American continent and the atmosphere-ocean system in the SEP are extremely important components of both the regional and global climate. The great height and length of the Andes Cordillera forms a sharp barrier to the zonal flow, resulting in a coastal jet of strong, low-level southerly winds parallel to the west coast of

Published by Copernicus Publications on behalf of the European Geosciences Union. 
South America (Garreaud and Muñoz, 2005). This, in turn, drives intense coastal oceanic upwelling, bringing cold, deep, and nutrient/biota rich waters to the surface. As a result, the SST is colder along the Chilean and Peruvian coasts than at any comparable latitude elsewhere in the world. The cold surface in combination with subsiding warm, dry air aloft is ideal for the formation of marine boundary layer clouds. In the observations, these extend almost $2000 \mathrm{~km}$ west from the Peruvian Coast and form the world's largest and most persistent subtropical stratocumulus cloud deck (Klein and Hartmann, 1993; Kollias et al., 2004).

The existence of this stratus cloud deck has a major impact on the earth's radiation budget (Ma et al. 1996; Gordon et al. 2000). Difficulties in the prediction of marine boundary layer clouds in climate models significantly contribute to uncertainties in the tropical cloud feedback (Bony and Dufresre, 2005). Most atmosphere-ocean coupled general circulation models (CGCMs) lack the ability to produce realistic cloud decks in the eastern tropical oceans (Mechoso et al., 1995; Ma et al., 1996, Hannay et al., 2009). The current and earlier operational versions of the National Centers for Environmental Prediction (NCEP)'s Global Forecast System (GFS) are among the CGCMs that suffer from such problem. Underprediction of stratus results in overestimation of heat flux into the ocean and may be the primary reason why ocean-atmosphere coupled models show positive SST biases of several degrees off the coast of Peru (Mechoso et al., 1995; Wang et al., 2005; de Szoeke et al., 2006).

These model difficulties with marine boundary layer clouds in the eastern tropical oceans are evident in the 2003 version of the operational GFS, which has been used since 2003 as the atmospheric component of the Climate Forecast System (CFS) to produce operational climate forecasts at NCEP (Saha et al., 2006). The CFS forecasts have large errors in the simulated mean SST, especially along the South American coast and in the Pacific "equatorial cold tongue" region. These errors are primarily attributable to the lack of sufficient stratocumulus that results in an incorrect simulation of the surface radiation budget. The CFS, however, obtains an ENSO-like interannual variation in the tropical Pacific with reasonable temporal and spatial patterns (Wang et al., 2005).

At NCEP, several approaches are being followed to improve the representation of cloudiness in the SEP and over the subtropical oceans in general. The present paper reports on a series of studies aimed at improving the simulation of stratocumulus in the operational GFS/CFS when running in simulation mode, i.e., for a period long enough to establish a model climatology. We search for simple yet physically based revisions of the representation of a low-level inversion - temperature/moisture jumps in the lower atmosphere and their control on the depth of shallow convection. The revisions described in this paper have been implemented in the CFS reanalysis (CFSR), which shows their beneficial impact (Moorthi et al., 2009).
The text is organized as follows. We start in Sect. 2 by providing a brief description of the operational NCEP/GFS. Section 3 presents the changes made to the GFS physics to improve the simulation of tropical marine stratocumulus. Section 4 describes the experiments performed with the model in order to assess the impact of the modifications. Sections 5, 6, and 7 describe and discuss the results from the experiments. Section 8 summarizes the work presented and conclusions reached.

\section{Brief description of the GFS}

The 2009 version of the GFS uses a spectral triangular truncation of 382 waves (T382) in the horizontal (equivalent to a nearly $35 \mathrm{~km}$ Gaussian grid), and a hybrid sigma-pressure finite differencing system (Sela, 2009) in the vertical with 64 layers. The model top layer is at $\sim 0.2 \mathrm{hPa}$.

This GFS version has undergone significant improvements from the version of the NCEP model used for the NCEP/NCAR Reanalysis (Kalnay et al., 1996; Kistler et al., 2001). These include upgrades in the parameterization of solar radiation transfer (Hou et al., 1996; Hou et al., 2002), planetary boundary layer (PBL) vertical diffusion (Hong and Pan, 1996), Simplified Arakawa-Schubert (SAS) cumulus convection (Pan and Wu, 1995; Hong and Pan, 1998), and gravity wave drag (Kim and Arakawa, 1995). In addition, cloud condensate is a prognostic variable (Moorthi et al., 2001) with a simple cloud microphysics parameterization (Zhao and Carr, 1997; Sundqvist et al., 1989). Both largescale condensation and the detrainment of cloud water from cumulus convection provide sources of cloud condensate.

The fractional cloud cover used in the radiation calculation is diagnostically determined from the predicted cloud condensate based on the approach of Xu and Randall (1996). The contribution of convection to cloud cover is through detrained condensate only; there is no explicit "convective cloud cover". The operational GFS also uses the Rapid Radiative Transfer Model (RRTM) longwave parameterization from Atmospheric and Environmental Research Inc. (AER, Mlawer et al., 1997) with maximum/random cloud overlap and a modified version of the National Aeronautics and Space Administration (NASA) Goddard Space Flight Center (GSFC) shortwave radiation (Hou et al., 2002; Chou et al., 1998) with random overlap. The latter scheme is known to overestimate shortwave radiation under cloudy conditions.

Ozone is a prognostic variable with a simple parameterization for ozone production and destruction. The model also incorporates the four-layer Noah community land-surface model (Ek et al., 2003). In addition to gravity-wave drag, a parameterization of mountain blocking (Alpert, 2004) is included, following the subgrid-scale orographic drag parameterization by Lott and Miller (1997).

The shallow convection parameterization follows Tiedtke (1983), and is applied wherever the deep convection 
parameterization is not active. In this scheme, the shallowconvective cloud top is defined as the highest layer below $0.7 *$ Ps for which a test parcel from the second model layer is positively buoyant. The cloud base is the Lifting Condensation Level (LCL) for the same test parcel. Enhanced vertical eddy diffusion is applied to temperature and specific humidity within this cloud layer; the diffusion coefficients are prescribed with a maximum value of $5 \mathrm{~m}^{2} \mathrm{~s}^{-1}$ near the cloud center and approach zero near the edges.

The PBL scheme in the GFS is based on the Troen and Mahrt (1986) paper and was implemented by Hong and Pan (1996). The scheme is a first-order vertical diffusion scheme. The PBL height is diagnostically determined by the bulkRichardson approach. Once the PBL height is determined, the profile of the coefficient of diffusivity is specified as a cubic function of the PBL height. There is also a countergradient flux parameterization that is based on the fluxes at the surface and the convective velocity scale.

\section{Modifications of the GFS}

The parameterization of shallow convection has an important influence on the simulated formation and/or destruction of marine stratocumulus. Wang et al. (2004) found that turning off the shallow convection parameterization in their regional model simulations dramatically increased the boundary layer cloud amount. De Szoeke et al. (2006) examined the effect of shallow convection on the eastern Pacific climate using a regional ocean-atmosphere model. They found that shallow convection acts to reduce stratus cloud formation and that with no shallow convection stratiform cloud fraction increases, resulting in an excessive SST cooling.

Strong low-level inversions are expected to limit the vertical extent of shallow clouds. In the GFS version we started with, however, the existence of a low-level inversion was ignored and shallow clouds were allowed to extend from the LCL up to $0.7 \mathrm{P}_{s}$. Thus, they could actually extend across the inversion layer irrespective of its strength, leading to its erroneous weakening in all cases. This process also resulted in excessive drying and warming of the layers below the inversion, where the cloud amount was severely limited. Therefore, as a first step we introduce consideration of the lowlevel inversion into the shallow convection scheme of the GFS.

A low-level inversion is defined as the region comprised of model layers below $0.65 \mathrm{P}_{s}$ in which $d T / d P$ ( $T$ and $P$ are temperature and pressure, respectively) satisfies the following requirements: (i) is less than $0.0001 \mathrm{~K} / \mathrm{Pa}$, and (ii) changes sign at one or two of the layers below. Next, we require the mixing associated with shallow convection to be confined below the inversion when the inversion is stable enough as measured by a parameter based on the cloud-top entrainment instability (CTEI) concept. This concept has been used in GCMs for several decades in an attempt to rep- resent a large-scale control on PBL clouds (Deardorff, 1980; Randall, 1980; Suarez et al., 1983). In its original formulation, CTEI predicts runaway entrainment and rapid destruction of stratocumulus when the following condition holds,

$\kappa=c_{p} \Delta \theta_{e} / L \Delta q_{t}>\kappa_{0}$,

where $c_{p}$ is the specific heat of dry air under constant pressure, $L$ is the latent heat of water vaporization, $\Delta \theta_{e}$ is the jump of equivalent potential temperature, and $\Delta q_{t}$ is the jump of total water mixing ratio across the inversion. According to Randall (1980) and Deardorff (1980) an appropriate value to be used in the right hand side of (1) is $\kappa_{0}=0.23$. As pointed out by many authors (e.g., Kuo and Schubert, 1988; Moeng, 2000; Stevens et al., 2005; Siems et al., 1990), Eq. (1) only gives the possibility of buoyancy reversals when entrained air is mixed with cloudy air and cooled by cloud water evaporation. Clouds may still remain and entrainment may not change abruptly because (a) the fraction of denser mixtures generated during entrainment mixing for $\kappa$ larger than $\kappa_{0}$ may be too small to cause instability, and (b) these denser mixtures may not directly enhance the intensity of entraining eddies at the cloud top. Other possible responses to entrainment drying, like enhanced surface moisture flux or reduced cloud-top radiative cooling, could either refill the cloud gaps or reduce the intensity of entraining eddies. Despite these caveats, Large Eddy Simulation Models (LES) in cases with both well-mixed and decoupled PBL setups have shown significant anti-correlation between cloud fraction and $\kappa$ (Moeng 2000; Lock 2009). For $\kappa$ large enough (0.6 0.7), values of cloud fraction are around $0.1 \sim 0.2$. This suggests that, even though satisfying threshold conditions like $\kappa>\kappa_{0}$ does not lead to the immediate destruction of cloud-topped boundary layers, $\kappa$ seems to be a good empirical indicator of the stability of stratocumulus decks and a transition to shallow cumulus regime is expected for very large $\kappa$. The LES study by Xiao et al. (2010) also suggests that in a decoupled boundary layer with active cumulus updrafts, $\kappa$ is a good measure of the stability of the inversion-capped stratocumulus layer. On the basis of the above empirical evidence and theoretical arguments, we propose that in models (like the GFS) that are not designed to fully resolve the detailed turbulent structure of cloud-topped boundary layers, $\kappa$ can be used as a physically based large-scale parameter determining whether the inversion is unstable enough to allow large entrainment mixing and consequent destruction of stratocumulus in the presence of cumulus updrafts. In this framework we allow mixing associated with shallow convection to extend across the inversion only when Eq. (1) is satisfied. In this study we chose $\kappa>\kappa_{0}=0.7$ following MacVean and Mason (1990). There are other more sophisticated versions of Eq. (1), which quantitatively take into account the liquid water amount near the cloud top (e.g., Nicholls and Turton, 1986; Lilly, 2002). For our current study, we want to first establish the effectiveness of the CTEI criteria in controlling low cloud amount. Additional dependence on cloud 
Table 1. List of experiments performed in this study.

\begin{tabular}{lll}
\hline & CTEI-condition & ZEROBD-condition \\
\hline CONTROL & No & No \\
CTEI & Yes & No \\
ZEROBD & No & Yes \\
CZ & Yes & Yes \\
\hline
\end{tabular}

top liquid water amount will be implemented later on with a sophisticated shallow convection scheme.

The GFS also includes a background eddy vertical diffusion to enhance mixing close to the surface, where the eddy diffusion calculated by the boundary layer parameterization is considered inadequate. The coefficient of background diffusion decreases exponentially with pressure, with the surface value set to $1.0 \mathrm{~m}^{2} \mathrm{~s}^{-1}$. For the SEP region, particularly near the coast of South America, the inversion height usually is very low due to strong subsidence. Therefore, the background vertical diffusion is strong enough to weaken the inversion and allow moisture exchanges with the free atmosphere. Since we have a defined inversion height we can now zero out the background diffusion in the layers above the inversion.

\section{Description of the experiments}

We performed a total of four sets of GFS experiments using observed SSTs (see Table 1). Each set has six two-month integrations starting at initial conditions corresponding to 00:00 UTC daily from 13 to 18 June 2008. In these experiments we used a T126 version of the model and version 2 of the Relaxed Arakawa-Schubert (RAS) parameterization of deep convection (Moorthi and Suarez, 1992, 1999). The primary focus for the analyses is the ensemble means for July in the region between the Equator to $40^{\circ} \mathrm{S}$ and $110^{\circ} \mathrm{W}-70^{\circ} \mathrm{W}$, which we will refer to as the SEP in the remainder of this paper. All the cross-sections used in the following sections are along $20^{\circ} \mathrm{S}$. This is the line VOCALS observation took place. In the future we may compare our simulation results with VOCALS observations.

1. The CONTROL experiment was done with the operational treatment of shallow convection and background diffusion as described in Sect. 3.

2. The CTEI experiment is the same as the CONTROL, except that a low-level inversion is defined and the criterion for instability expressed by Eq. (1) is used (CTEIcondtion).

3. The ZEROBD experiment is the same as the CONTROL, except that the background diffusion is set to 0 above the inversion (ZEROBD-condition).

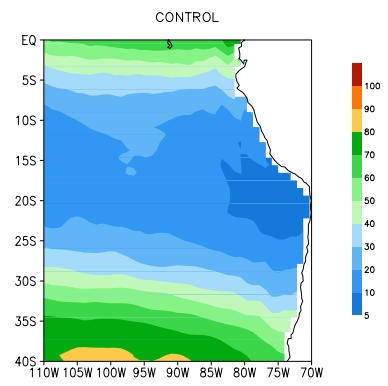

ZEROBD
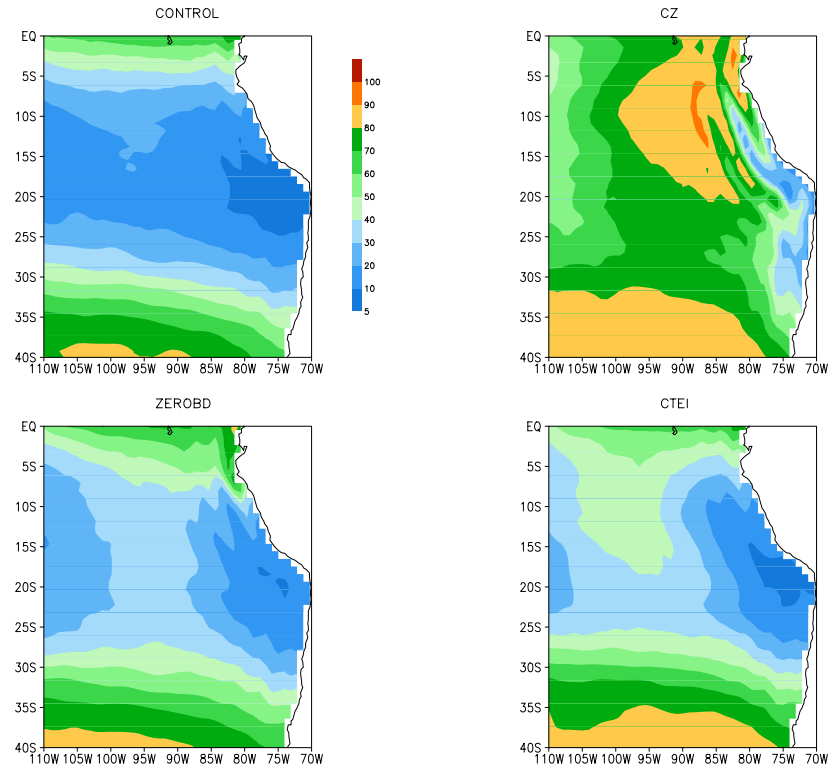

CTE

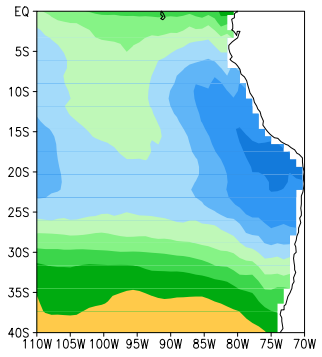

Fig. 1. The ensemble July 2008 mean total cloud cover in the SEP region in all four experiments.

4. The CZ experiment has both the CTEI-condition and the ZEROBD-condition.

\section{Results}

\subsection{Cloud cover and cloud water}

Figure 1 shows the ensemble mean total cloud cover for July 2008 in the SEP region for the four experiments, and Figure 2 displays an observed climatology for 1985-1993 from the International Satellite Cloud Climatology Project (ISCCP). There is too little cloudiness in the CONTROL and the two single modification experiments (ZEROBD and CTEI). CONTROL produces the least total cloud amount, and CTEI obtains a little more cloud than ZEROBD. CZ produces the best total cloudiness compared with the ISCCP observations. Specifically, the large area of minimal cloud cover near the South American coast, due to the lack of stratocumulus in the other three cases, is now replaced by a local maximum (mostly low clouds, see Fig. 3) except very near the coast. Furthermore, the values for total cloud in the region between $5 \mathrm{~S}$ and $30 \mathrm{~S}$ obtained in $\mathrm{CZ}$ are much higher than those in the field defined at each point by the maximum of ZEROBD and CTEI (figure not shown). We can say that realistic stratocumulus decks only exist in the CZ experiments. Section 6 discusses the reasons for this feature.

Figure 3 shows the ensemble mean low-cloud cover for July 2008 in all four experiments while Fig. 4 presents an observed climatology from ISCCP. The CONTROL produces too few low clouds, the least among the four experiments. The CTEI-condition is a little more effective than 


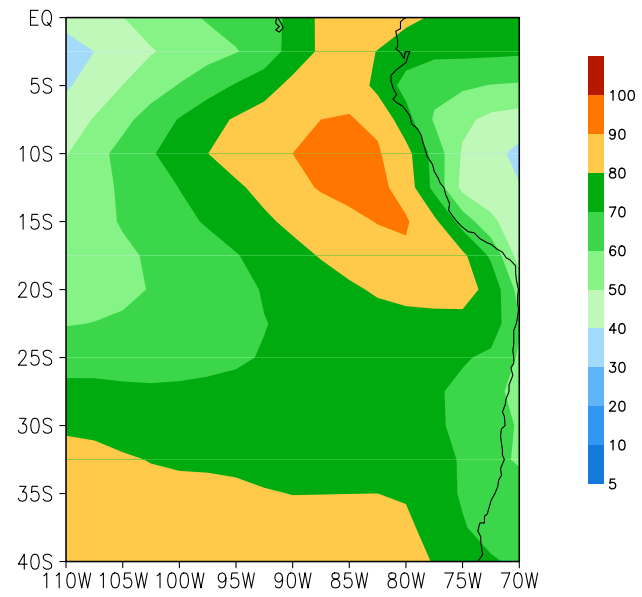

Fig. 2. The ISCCP July mean (1985-1993) total cloudiness in July in the SEP region.

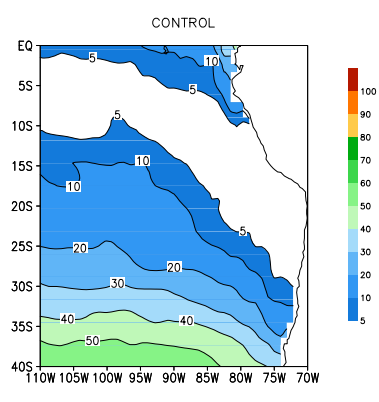

ZEROBD

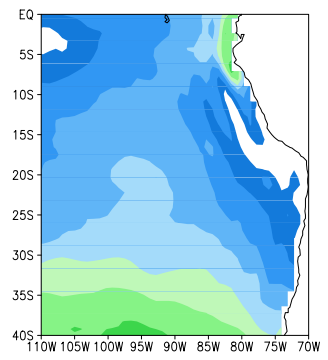

$\mathrm{cz}$

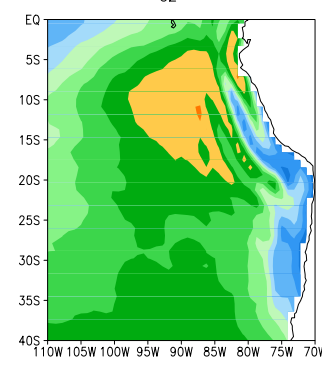

CTEI

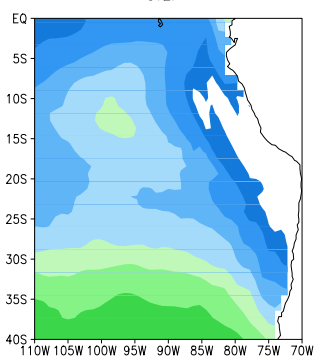

Fig. 3. As in Fig. 1 except for low clouds.

the ZEROBD-condition in producing low clouds. The CZ experiment obtains the highest low-cloud amounts, which are even higher than in the ISCCP climatology. Since the total cloud cover in $\mathrm{CZ}$ is less than in the ISCCP climatology, this result suggests a mismatch between the cloud types in the simulations and the ISCCP climatology. There may be many reasons for this mismatch. One obvious reason is that low clouds in the GFS are those between $1000 \mathrm{hPa}$ to $680 \mathrm{hPa}$, while in the ISCCP they are below $642 \mathrm{hPa}$. Another reason is that the ISCCP tends to underestimate low-cloud cover (Chang and Li, 2005; comments also made by Chris Fairall at the Second VOCALS meeting in Seattle, 2009). A comparison between Figs. 1 and 3 shows that in CZ all the clouds in the SEP are low clouds.



Fig. 4. As in Fig. 2 except for low clouds.
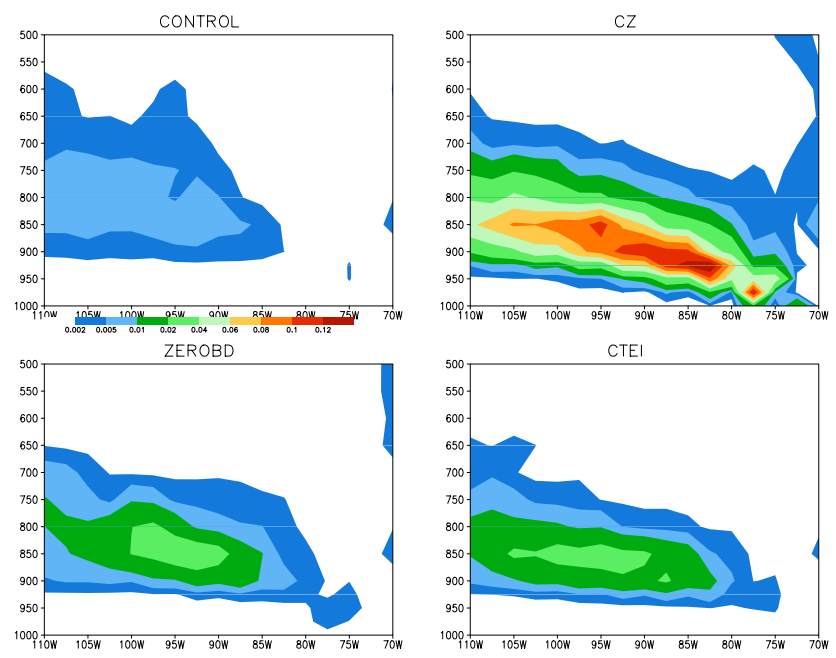

Fig. 5. Vertical cross-section of monthly mean cloud water in July along 20S.

Figure 5 shows the vertical structures of ensemble mean cloud water for July 2008 in the SEP along $20^{\circ} \mathrm{S}$. Most of the cloud water produced in the CONTROL is located off the coast. The CTEI and ZEROBD experiments both obtain more cloud water near the coast and at low levels than the CONTROL. The CZ experiment obtains the most cloud water, especially at lower levels close to the coast.

\subsection{Radiation}

Radiative fluxes at the surface and the top of the atmosphere in the simulations are examined and compared with the corresponding flux climatology for 1984-1994 compiled by the Surface Radiation Budget (SRB) project (http: //GEWEX-SRB.larc.nasa.gov/). Since the ISCCP data on cloud amount were used to build the SRB dataset, some degree of consistency between the two datasets is expected. 

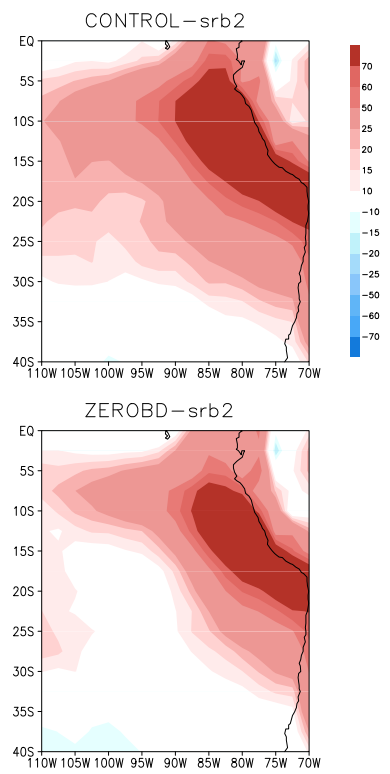

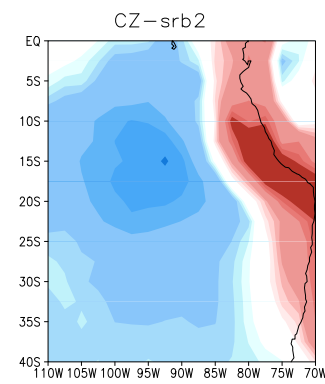

CTEI-srb2

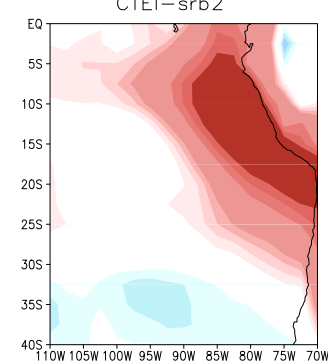

Fig. 6. The ensemble July 2008 mean surface downward shortwave radiative flux errors (differences between the four simulations and SRB climatology).

Figure 6 shows the July ensemble mean short-wave radiative flux errors at the surface. In general, the short-wave radiative flux at the surface is, as expected, too large in the CONTROL, ZEROBD, and CTEI experiments since cloudiness in the experiments is lower than in the ISCCP climatology. The short-wave radiative flux at the surface in $\mathrm{CZ}$ is smaller than that in SRB across most of the SEP (except for the portion near the coast) due to more clouds in the simulation than in the climatology. It should be pointed out that tuning the microphysics, shortwave parameterization, or value of the CTEI parameter could alleviate the excessive shortwave absorption. For example, it is known that the absorption of shortwave radiation by the atmosphere is too high in the shortwave parameterization in this version of the GFS (Y. Hou, personal communication, 2008). In terms of the downward long-wave radiative flux at the surface, Figure 7 shows that $\mathrm{CZ}$ is much better than the other three experiments. The difference in long-wave radiative flux at the surface between $\mathrm{CZ}$ and the SRB climatology is small, except near the coastal region. In the other 3 experiments the long-wave radiative fluxes at the surface are mostly smaller than the climatology due to the underestimation of low clouds. Figure 8 shows the July ensemble mean of upward shortwave radiative flux errors at the top of the atmosphere (TOA). The radiative fluxes at the TOA also reflect the cloudiness in the simulations. More upward short-wave radiative flux is produced at the TOA in CZ than in the other three simulations because the others produce less cloudiness. Compared with the SRB climatology, the upward shortwave radiative flux away from the coast at the TOA is too large in $\mathrm{CZ}$ and too small in the other three
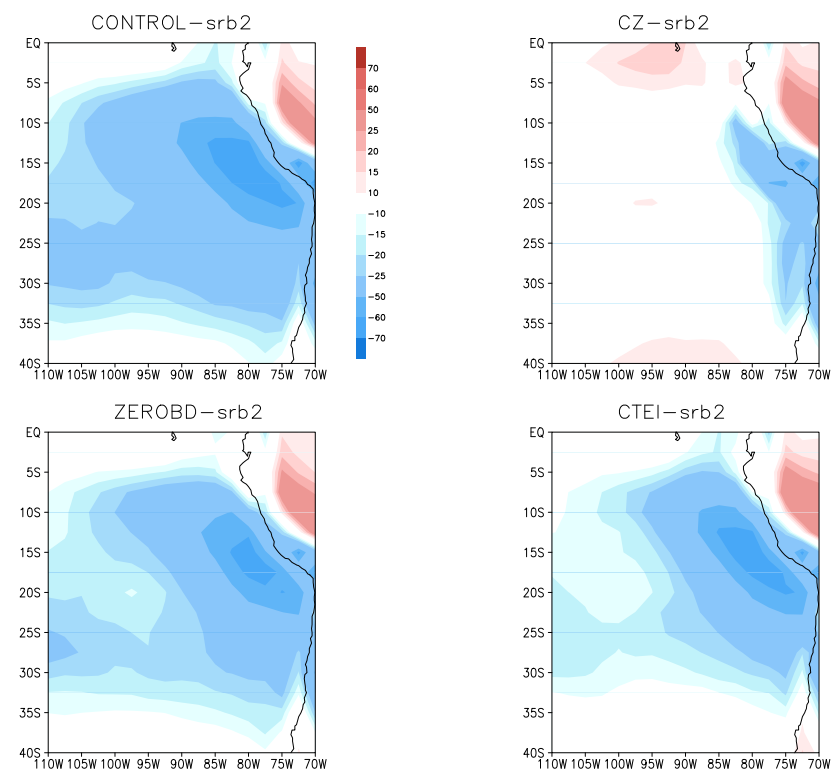

Fig. 7. As in Fig. 6 except for longwave radiative flux errors.
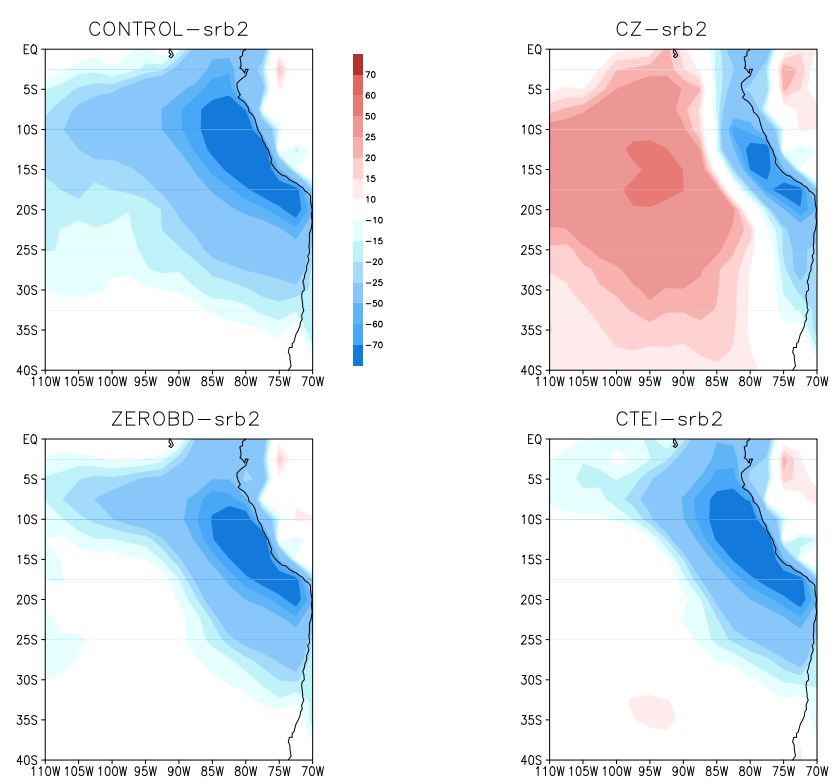

Fig. 8. The July 2008 ensemble mean upward shortwave radiative flux errors (difference between the simulations and SRB climatology) at the top of the atmosphere in the four experiments.

simulations. The outgoing long wave radiation (OLR) errors at the TOA are illustrated in Fig. 9. Values of OLR are large in all simulations compared with the observations. Overpredicted OLR is consistent with overpredicted low cloud and underpredicted higher clouds in $\mathrm{CZ}$ as suggested by Figs. 1 and 3 , and underpredicted cloud amounts in other three experiments. The differences in OLR between $\mathrm{CZ}$ and the SRB climatology are the smallest. 


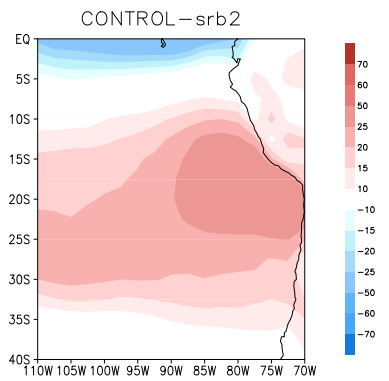

ZEROBD-srb2

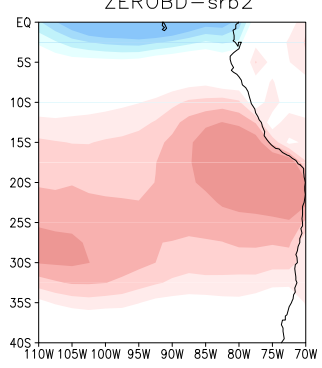

$c Z-s r b 2$

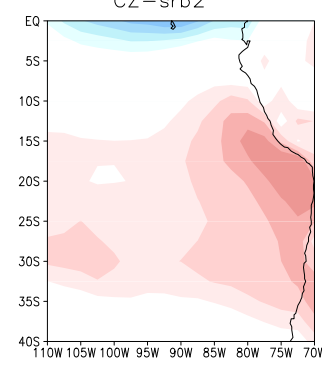

CTEI-srb2



Fig. 9. As in Fig. 8 except for the longwave radiative flux errors.

\section{Relative impact of ZEROBD and CTEI-conditions}

The shallow convection scheme in the GFS acts through enhanced diffusion in the cloudy layers. The scheme warms and dries the lower layers and cools and moistens the upper layers. Figure 10 shows vertical cross-sections of ensemble mean moistening rates due to shallow convection along $20^{\circ} \mathrm{S}$ from $110^{\circ} \mathrm{W}$ to $70^{\circ} \mathrm{W}$ in the four experiments for July 2008. Mixing is most intense in the CONTROL, while among the 3 experiments it is much stronger in ZEROBD than in CTEI and CZ. The mixing layers in the CONTROL and ZEROBD are also deeper than in CTEI and CZ. We posit that the reduced shallow convective mixing across the inversion in $\mathrm{CZ}$ and CTEI is the main reason for the increased clouds in these two experiments. The reduced mixing is consistent with more moisture being trapped at low levels in CZ and CTEI than in the other two experiments. Thus, the large-scale condensational processes (microphysical processes) and, to a certain extent, RAS, take over to produce more clouds. While this hypothesis is consistent with the differences in cloud amount between CONTROL (ZEROBD) and CTEI (CZ), it alone cannot explain the large difference in cloud amount between CZ and CTEI. As we can see from Fig. 10, the difference in shallow convective mixing between the two experiments is not that large even when taking into account the difference in the equilibrium moisture gradients across the inversion.

The ZEROBD-condition also reduces the mixing of moisture and temperature across the inversion by turning off background diffusion. This also contributes to a reduction in mixing due to shallow convection by increasing inversion strength, which lowers convective available potential energy
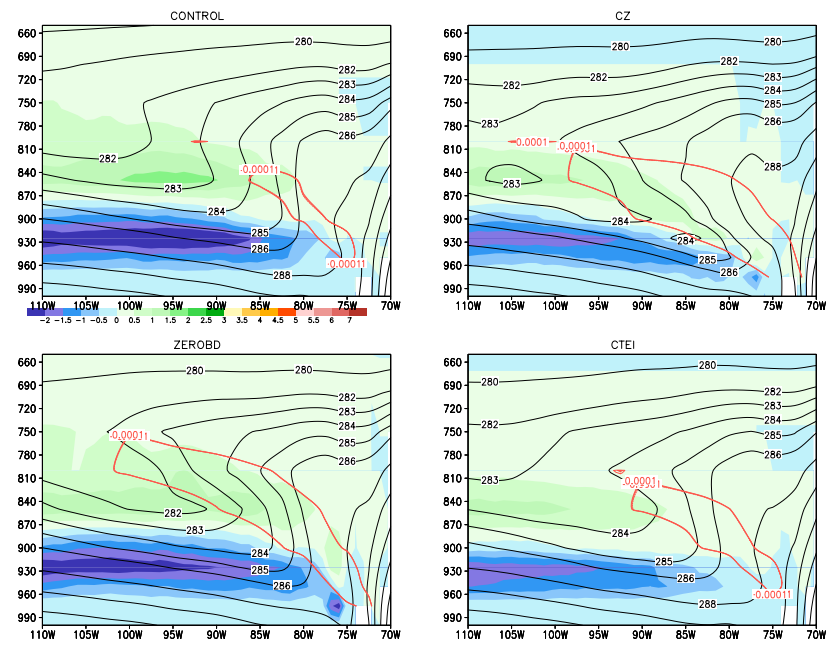

Fig. 10. Vertical cross-sections of ensemble monthly mean moistening rates $\left(\mathrm{g} / \mathrm{kg} /\right.$ day) along $20^{\circ} \mathrm{S}$ (shaded) due to shallow convection in the four experiments. Black contours represent the vertical crosssection of temperature. Red contours represent estimated inversion.

(CAPE) and reduces the chance of shallow convection activity. This is illustrated by the comparison between the CONTROL and ZEROBD in Fig. 10. When the CTEI and ZEROBD conditions are applied jointly in $\mathrm{CZ}$, the increase in the strength of the inversion due to ZEROBD-condition may also "indirectly" affect shallow convection by acting through the CTEI condition. With a stronger inversion, the CTEIcondition tends to allow even less shallow convection activity according to Eq. (1). The ZEROBD-condition, therefore, contributes to less diffusive inversions in $\mathrm{CZ}$ than in CTEI. However, again as shown in Fig. 10, the difference due to reduced background diffusion alone does not seem to be enough for the differences in cloud amount between $\mathrm{CZ}$ and CTEI.

To further investigate the differences between $\mathrm{CZ}$ and the CTEI, we examine the moistening rates due to vertical turbulent diffusion associated with the PBL parameterization (hereafter VTD, which includes background diffusion) and convection parameterization (RAS). Although RAS transports moisture from the lower to upper levels it is not the main reason for the large difference in cloud amount between $\mathrm{CZ}$ and CTEI (figure is not shown). Figure 11 shows the vertical cross-sections of ensemble monthly mean moistening rates due to VTD along 20S. The moistening rate due to VTD in $\mathrm{CZ}$ is the largest among the experiments and is much larger than in CTEI. More moisture is transported to upper levels from the near surface in CZ than in CTEI, which contributes to maintaining the larger cloud amounts in the former experiment. The reasons for the difference in VTD between the two experiments may include a positive feedback involving radiation-turbulence interaction in the PBL, as will be discussed later. Figure 11 also shows that the moistening rate 



Fig. 11. As in Fig. 10 except for moistening rates (g/kg/day) (shade) due to vertical turbulent diffusion.

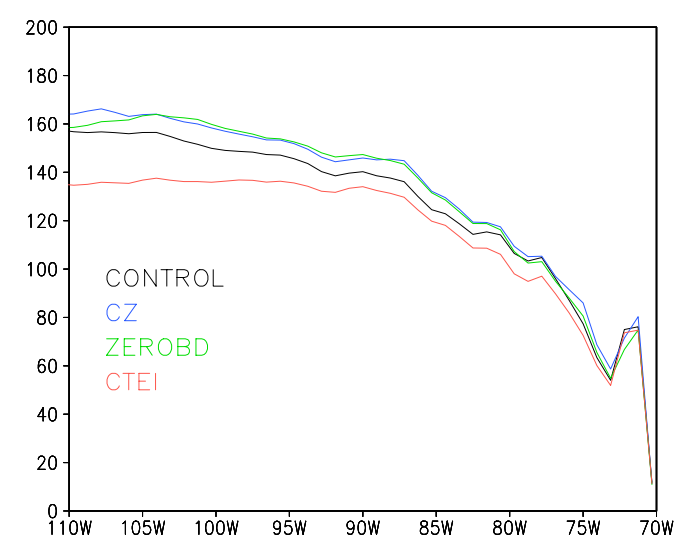

Fig. 12. July 2008 ensemble mean latent heat flux $\left(\mathrm{W} / \mathrm{m}^{2}\right)$ at the surface along $20 \mathrm{~S}$

due to VTD in CTEI is even smaller than in either CONTROL or ZEROBD. Cloud amount, on the other hand, is larger in CTEI than in the CONTROL and ZEROBD because of mixing due to shallow convection. This again illustrates the effectiveness of CTEI-condition in trapping moisture below the inversion. The weaker moistening rate due to VTD in CTEI compared to CZ (also to CONTROL and ZEROBD) is associated with weaker evaporation at the surface, as shown in Fig. 12. It is interesting to note the different moisture balances among the surface evaporation, VTD, and shallow convection in ZEROBD and CTEI. Moisture transport from the surface in ZEROBD is all consumed by the shallow convection, with little stratocumulus formation.

Figure 13 shows the ensemble monthly mean vertical cross-sections of heating rates (shaded) due to large-scale condensation/evaporation and temperature (contours) along $20^{\circ} \mathrm{S}$ in the four experiments. Positive heating rates (warming) due to large-scale condensation are found in CZ. The


Fig. 13. As in Fig. 10 except for the heating rate (K/day) (shaded) due to large-scale condensation.

most intense warming in $\mathrm{CZ}$ happened roughly below the inversion (the inversion height changes with longitude and time), which is where most clouds are produced. This suggests that large-scale condensation is the main process producing the clouds in CZ. RAS helps to produce clouds through the detrainment of cloud water at the cloud top. RAS also indirectly contributes to the cloud production in CZ by reducing mixing caused by shallow convection. This is because shallow convection is shut off whenever RAS is activated unless the cloud depth is less than $200 \mathrm{hPa}$. The negative heating rates (cooling) in the CONTROL, ZEROBD, and CTEI and at low levels in CZ (see Fig. 13) are due to the evaporation of cloud and rainwater.

The large difference in moistening rates due to VTD in $\mathrm{CZ}$ and CTEI are probably associated with the differences in radiative cooling and stability in the boundary layer. A possible scenario is that the lower mixing across the inversion in CZ than in CTEI leads to more stratus clouds in CZ, which results in more long-wave radiative cooling at the cloud top and a more unstable PBL. This leads to more intense VTD and stronger surface evaporation. With more moisture transported from surface to upper levels by VTD in CZ than in CTEI, more clouds are produced in CZ. This forms a positive feedback. Figure 14 shows the difference in the radiative heating rate (long-wave plus short-wave) in the two experiments. With strong and persistent radiative cooling affecting the vertical mixing in the cloud layer through the PBL parameterization, CZ obtains a different (stratocumulus) cloud regime than the others, which tend to a shallow cumulus regime where radiative forcing plays no important role in regulating the vertical mixing. This is a clear example of how allowing the radiation to affect turbulence, even if only by affecting large-scale stability as in our case, could change the picture. 

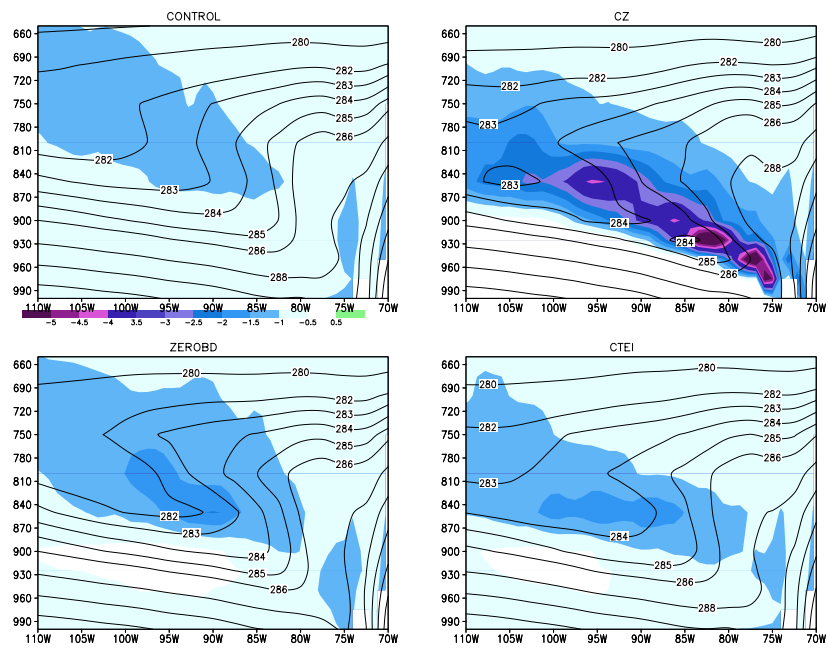

Fig. 14. As in Fig. 10 except for radiative heating rate (K/day) (shaded).

The positive feedback proposed here is different from that discussed by Wang et al. (2005). In their regional study of marine boundary layer clouds in the SEP Wang et al. argued that there is a positive feedback between radiative cooling and large-scale dynamic warming, which maintains the inversion and the boundary layer clouds. We examined vertical velocity field in our simulations and did not see the occurrence of peak velocity in the cloudy regions.

This distinction between the $\mathrm{CZ}$ experiment and the others can also be seen in the vertical distribution of moisture. Figure 15 shows the July mean total water mixing ratio at $80^{\circ} \mathrm{W}, 20^{\circ} \mathrm{S}$ for the four cases. Compared to the $\mathrm{CZ}$ cases, these other cases show what we commonly found in current generation GCMs in this region. The low-level moisture profiles in these cases have rather smooth vertical moisture gradient, and it is difficult to even define the inversion using their moisture gradients. In $\mathrm{CZ}$, the moisture profile improves, with larger values near the top of the PBL (910-950 mb) and much smaller values just above $900 \mathrm{mb}$, thus producing a better defined inversion.

\section{Impacts on global precipitation}

Figure 16 shows the July 2008 mean global precipitation rate ( $\mathrm{mm} /$ day) in the four experiments. The Climate Prediction Center (CPC) Merged Analysis of Precipitation (CMAP; Xie and Arkin 1996) 2008 July mean precipitation rate (mm/day) is shown in Fig. 17. The differences in precipitation rate are not large among the four experiments. An interesting feature that occurs only in $\mathrm{CZ}$ is the $1-2 \mathrm{~mm} /$ day precipitation rate in the SEP region. This light precipitation is primarily caused by large-scale processes. In reality, this is the region where drizzle occurs. When compared with the CMAP climatology most of the main precipitation features are reproduced in the

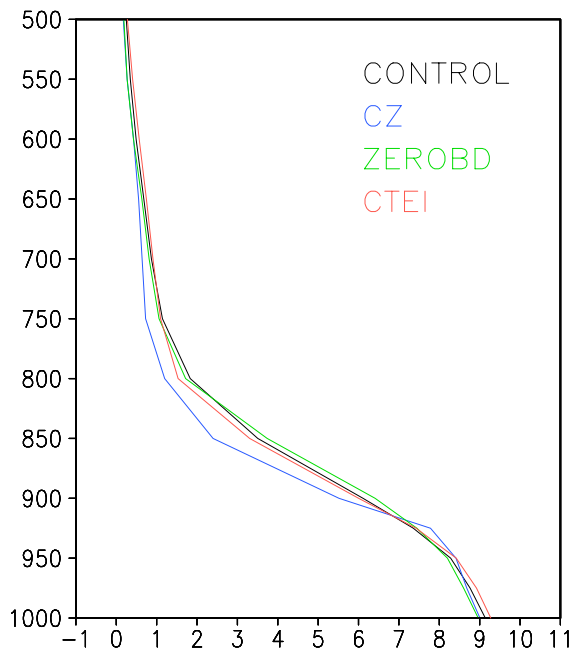

Fig. 15. July 2008 ensemble mean total water profile at $\left(20^{\circ} \mathrm{S}\right.$, $\left.85^{\circ} \mathrm{W}\right)$, vertical coordinate is $\mathrm{Pa}$ and horizontal coordinate is $\mathrm{g} / \mathrm{kg}$.

four experiments, such as the rain bands associated with the Intertropoical Convergence Zone (ITCZ), South Pacific Convergence Zone (SPCZ), mid-latitude oceanic storm tracks, and maxima over the continents at monsoon locations. But compared to the values in CMAP, the experiments produced too much precipitation over the western warm pool and too little precipitation over Indian Ocean south of Equator.

\section{Summary and discussion}

Several methods have been tested to alleviate an important systematic error in the NCEP GFS model: the lack of stratocumulus in the SEP region. The present paper describes two model modifications (a) the elimination of background vertical diffusion above the low-level inversion (ZEROBDcondition), and (b) the incorporation of a tunable parameter based on the CTEI criterion for determining cloud tops for the shallow convection parameterization when low-level inversions exist (CTEI-condition). Four experiments consisting of six-member sets of integrations were performed to examine both the individual and combined effects of the modifications on the simulation of stratocumulus clouds. It was found that both modifications contributed to enhance cloud generation in the SEP region. The CTEI-condition is more effective than ZEROBD-condition in producing lowlevel clouds. However, ZEROBD-condition is also shown to be important, especially close to the coast. A comparison with the ISCCP climatology reveals that both modifications individually produced too little cloudiness. However, the two modifications applied together in $\mathrm{CZ}$ produced about the right amount of total cloudiness in the region. This combination, therefore, is much more effective than either of the two modifications alone. The reason for this nonlinearity is that both changes reinforce each other in reducing the leakage 
CONTROL

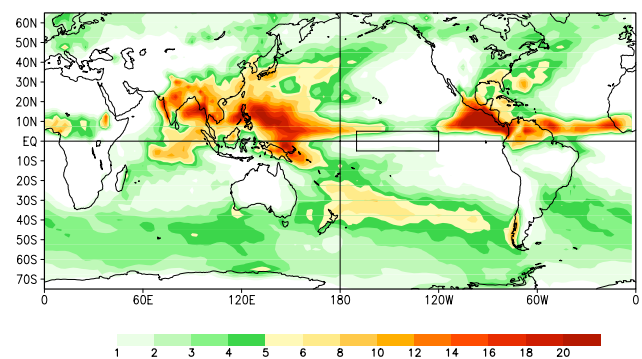

ZEROBD

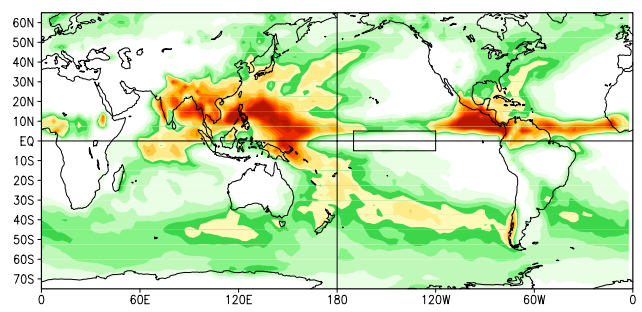

CZ

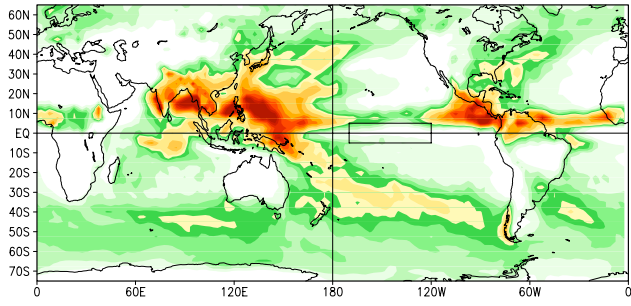

Fig. 16. The July 2008 mean precipitation rate ( $\mathrm{mm} /$ day) in the four experiments.

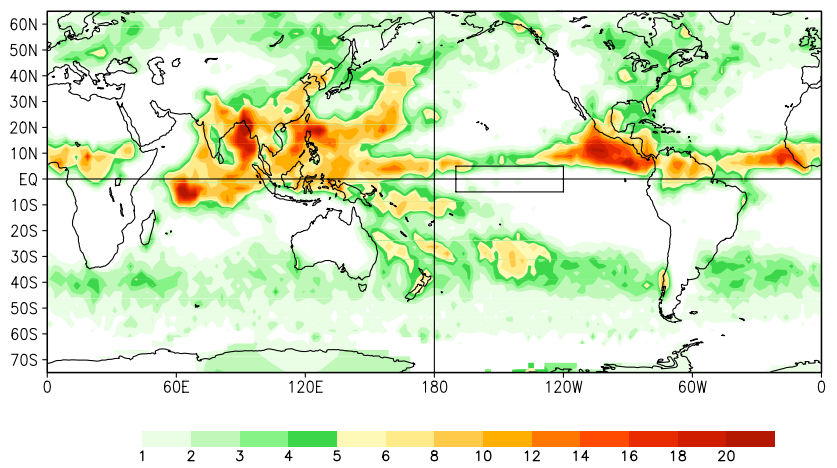

Fig. 17. The global July mean CMAP precipitation rate ( $\mathrm{mm} /$ day) averaged between 1979 and 2005 (Xie and Arkin, 1997).

of moisture across the inversion. Less mixing traps more moisture in lower levels below the inversion, which leads to an increase in cloud amount and cloud-top radiative cooling. Then, a positive feedback due to enhanced turbulent mixing in the PBL driven by cloud-top radiative cooling leads to and maintains the large stratocumulus cloud cover in CZ. This enhanced response in $\mathrm{CZ}$ also implies that the effectiveness of the CTEI-based algorithm is highly sensitive to the strength of the inversion. In generating clouds the largescale condensation process was the main contributor. The RAS scheme also provided a positive, but relatively small contribution. Although it was roughly of the correct magnitude, the amount of total cloudiness obtained in the simulation with both modifications $(\mathrm{CZ})$ may produce different low, middle, and high cloud amounts than the observations. The availability of reliable observations of the vertical distribution of cloud water will be very helpful for verifying the performance of climate models in the simulation of such features. The impacts of this mismatch on the coupled climate system simulation have yet to be studied.

Our experiments have demonstrated that it is possible to simulate realistic marine boundary clouds in large-scale models with direct and physically based changes in the major model parameterizations. We are currently considering several revisions to further improve upon the results of $\mathrm{CZ}$, which tends to generate too much stratocumulus in the core region. First, NCEP is currently moving towards implementing in its operational models the RRTM shortwave radiation parameterization with maximum/random overlap. This radiation scheme has less shortwave absorption in the clouds, which together with a slightly tuned microphysics should further improve the surface shortwave radiation at the ocean surface. Second, the direct effect of cloud radiative processes on turbulent mixing in the boundary layer, and in the shallow convection layer below the inversion is being incorporated into the GFS. Third, for a better simulation of the transition between the stratocumulus and shallow cumulus regimes in the SEP, we need to consider the decoupling between cloud and sub-cloud layers since decoupling is associated with more vigorous cumulus growth in the cloud layer, thus favoring penetrative convection across the inversion. At the present time, the two modifications presented in this paper have been implemented in the new CFS model and reanalysis (Saha et al., 2010). Another method addressing the 
lack of stratocumulus in the SEP region in the NCEP GFS is based on the mass-flux concept and the modified SAS. Tests have show very promising results.

Acknowledgements. This project is supported by National Oceanic and Atmospheric Administration NA07OAR4310236. SRB data were obtained from the NASA Langley Research Center Atmospheric Sciences Data Center NASA/GEWEX SRB Project. We would like to thank Mary Hart for correcting grammar, Huiya Chuang for her help with the $\mathrm{d} 3 \mathrm{~d}$ analysis and Hualu Pan, Jongil Han, Fanglin Yang, Xingren Wu, and others at EMC for their generous help with the GFS/CFS. We appreciate helpful comments from Brad Ferrier, Glenn White, and Masayuki Nakagawa during their internal reviews and Yuqing Wang and Peter Caldwell during the peer reviews of the manuscript. We would like to thank Stephen Lord for his support of this project.

Edited by: R. Wood

\section{References}

Alpert, J. C.: subgrid-scale mountain blocking at NCEP, Proc. Of 20th conf. on Weather and Forecasting, Seatle, WA, USA, 2004.

Bony, S. and Dufresre, J.-L.: Marine boundary layer clouds at the heart of tropical cloud feedback uncertainties in climate models, Geopys. Res. Lett., 32, L20806, doi:10.1029/2005GL023851, 2005.

Bretherton, C. S., and Wyant, M. C.: Moisture transport, lowertropospheric stability, and decoupling of cloud-topped boundary layers, J. Atmos. Sci.,54, 148-167, 1997.

Chang, F. and Li, Z.: A near-global climatology of single-layer and overlapped clouds and their optical properties retrieved from Terra/MODIS data using a new algorithm, J. Climate, 18, 47524771, 2005.

Chou, M. D., Suarez, M. J., Ho, C. H., Yan, M. M. H., and Lee, K. T.: Parameterizations of cloud overlapping and shortwave single scattering properties for use in general circulation and cloud ensemble models, J. Climate, 11, 202-214, 1998.

Deardorff, J. W.: Cloud top entrainment instability, J. Atmos. Sci., 37, 131-147, 1980.

Hannay, C., Williamson, D. L., Hack, J. J., Kiehl, J. T., Olson, J. G., Klein, S. A., Bretherton, C. S., and Köhler, M.: Evaluation of Forecasted Southeast Pacific Stratocumulus in the NCAR, GFDL, and ECMWF Models, J. Climate, 22, 2871-2889, 2009.

de Szoeke, S. P., Wang, Y., Xie, S.-P., and Miyama, T.: Effect of shallow cumulus convection on the eastern Pacific climate in a coupled model, Geophys. Res. Lett., 33, L17713, doi:10.1029/2006GL026715, 2006.

Ek, M. B., Mitchell, K. E., Lin, Y., Rogers, E., Grummann, P., Koren, V., Gayno, G., and Tarplay, J. D.: Implementation of the Noah land-use model advances in the NCEP operational mesoscale Eta model, J. Geophys. Res., 108, 8851, doi:10.1029/2002JD003296, 2003.

Garreaud, R. and Munoz, R.: The low-level jet off the subtropical west coast of South America: Structure and variablility, Mon. Weather Rev., 133, 2246-2261, 2005.

Gordon, C. T., Rosati, A., and Gudgel, R.: Tropical sensitivity of a coupled model to specificed ISCCP low clouds, J. Climate, 13, 2239-2260, 2000.
Hong, S.-Y. and Pan, H.-L.: Nonlocal boundary layer vertical diffusion in a medium range forecast model. Mon. Weather Rev., 124, 2322-2339, 1996.

Hong, S.-Y. and H.-L. Pan, 1998: Convective Trigger Function for a Mass-Flux Cumulus Parameterization Scheme, Mon. Wea. Rev., 126, 2599-2620.

Hou, Y.-T., Campana, K. A., and Yang, S. K.: Shortwave radiation calculations in the NCEP's global model, Int. Radiation Symposium, IRS-96, 19-24 August, Fairbanks, AL, USA, 1996.

Hou, Y., Moorthi, S., and Campana, K.: Parameterization of solar radiation transfer in the NCEP models, NCEP Office Note, 441. http://www.emc.ncep.noaa.gov/officenotes/FullTOC. html \#2000, 2002.

Kalnay, E., Kanamitsu, M., Kistler, R., Collins, W., Deaven, D., Gandin, L., Iredell, M., Saha, S., White, G., Woollen, J., Zhu, Y., Chelliah, M., Ebisuzaki, W., Higgins, W., Janowiak, J., Mo, K.C., Ropelewski, C., Wang, J., Leetmaa, A., Reynolds, R., Jenne, R., and Joseph, D.: The NCEP/NCAR 40-year Reanalysis Project, Bull. Amer. Meteorol. Soc., 77, 1057-1072, 1996.

Klein, S. A., and Hartmann, D. L.: The seasonal cycle of low stratiform clouds, J. Climate, 6, 1587-1606, 1993.

Kollias, P., Fairall, C. W., Zuidema, P., Tomlinson, J., and Wick, G. A.: Observations of marine stratocumulus in SE Pacific during the PACS 2003 cruise, Geophys. Res. Lett., 31, L22110, doi:10.1029/2004GL020751, 2004.

Kuo, H., and Schubert, W. H.: Stability of cloud-topped boundary layers. Q. J. Roy. Meteorol. Soc., 114, 887-917, 1988.

Lock, A. P.: Factors influencing cloud area at the capping inversion for shallow cumulus clouds, Q. J. Roy. Meteorol. Soc., 135, 941952, 2009.

Lilly, D.K., 2002: Entrainment into mixed layers. Part III: A new closure. J. Atmos. Sci., 59, 3353-3361.

Lott, F. and Miller M. J.: A new subgrid-scale orographic drag parameterization: Its performance and testing, Q. J. Roy. Meteorol. Soc., 123, 101-127, 1997.

Ma, C.-C., Mechoso, C. R., Robertson, A. W., and Arakawa, A.: Peruvian stratus clouds and the tropical Pacific circulation: A coupled ocean-atmosphere GCM study, J. Climate, 9, 1635-1645, 1996.

MacVean, M. K. and Mason, P. J.: Cloud-top entrainment instability through small-scale mixing and its parmeterization in numerical models, J. Atmos. Sci., 47, 1012-1030, 1990.

Mechoso, C. R., Robertson, A. W., arth, N., Davey, M. K., Delecluse, P., Gent, P. R., Ineson, S., Kirtman, B., Latif, M., Le Treut, H., Nagai, T., Neelin., J. D., Philander, S. G. H., Polcher, J., Schope, P. S., Stockdale, T., Suarez, M. J., Terray, L., Thual, O., and Tribbia, J. J.: The seasonal cycle over the tropical Pacific in coupled ocean-atmosphere general circulation models, Mon. Weather Rev., 123, 2825-2838, 1995.

Mlawer, E. J., Taubman, S. J., Brown, P. D., Iacono, M. J., and Clough, S. A.: Radiative transfer for inhomogeneous atmosphere: RRTM, a validated correlated-K model for the longwave, J. Geophys. Res., 102(D14), 16663-16682, 1997.

Moeng, C.-H.: Entrainment rate, cloud fraction and liquid water path of PBL stratocumulus clouds, J. Atmos. Sci., 57, 36273643, 2000.

Moorthi, S. and Suarez, M. J.: Relaxed Arakawa-Schubert. A Parameterization of Moist Convection for General Circulation Models, Mon. Weather Rev., 120, 978-1002, 1992. 
Moorthi, S. and Saurez, M. J.: Documentation of version 2 of Relaxed Arakawa-Schubert cumulus parameterization with convective downdrafts, NOAA Tech. Report NWS/NCEP 99-01, 44 pp., 1999.

Moorthi, S., Pan, H. L., and Caplan, P.: Changes to the 2001 NCEP operational MRF/AVN global analysis/forecast system, NWS Technical Procedures Bulletin, 484, 14 pp., available online at: http://www.nws.noaa.gov/om/tpb/484.htm, 2001.

Moorthi, S., Sun, R., Xiao, H., and Mechoso, C. R.: Southeast Pacific low-cloud simulation in the NCEP GFS: role of vertical mixing and shallow convection, NCEP Office Note, 463, 1-28, 2009.

Nicholls, S. K., and Turton, J. D.: An observational study of the structure of stratiform cloud streets. Part II: Entrainment, Q. J. Roy. Meteorol. Soc., 112, 461-480, 1986.

Pan, H.-L. and Wu, W.-S.: Implementing a mass flux convective parameterization package for the NMC medium range forecast model, NMC office note 409, 40 pp., available online at: http://www.emc.ncep.noaa.gov/officenotes/FullTOC. html, \#1990, 1995.

Randall, D. A.: Conditional instability of the first kind upsidedown, J. Atmos. Sci., 37, 125-130, 1980.

Saha, S., Nadiga S., Thiaw, C., Wang, J., Wang, W., Zhang, Q., Van den Dool, H. M., Pan, H.-L., Moorthi, S., Behringer, D., Stokes, D., Pena, M., Lord, S., White, G., Ebisuzaki, W., Peng, P., and Xie, P.: The NCEP climate forecast system, J. Climate, 19, 3483-3517, 2006.

Saha, S., Moorthi, S., Pan H.-L., Wu, X., Wang, J., Nadiga, S., Tripp, P., Kistler, R., Woollen, J., Behringer, D., Liu, H., Stoke, D., Grubine, R., Gayno, G., Wang, J., Hou, Y.-T., Chuang, H.-Y., Juang, H.-M. H., Sela, J., Iredell, M., Treadon, R., Kleist, D., Van Delst, P., Deyser, D., Derber, J., Ek, M., Meng, J., Wei, H., Yang, R., Lord, S., Van Den Dook, H., Kumar, A. Wang W., Long, C., Chelliah, M., Xue, Y., Huang, B. Schemm, J.-K., Ebisuzaki, W., Lin, R., Xie, P., Chen, M., Zhou, S., Higgins, W., Zou, C.-Z., Liu, Q., Chen, Y., Han, Y., Cucurull, L., Reynolds, R., Rutledge, G., and Goldber, M.: The NCEP climate forecast system reanalysis, Bull. Amer. Meteorol. Soc., accepted, 2010.

Sela, J.: Implementation of the sigma pressure hybrid coordinate into GFS, NCEP office Note \# 461, 1-25, available online at: http://www.emc.ncep.noaa.gov/officenotes/FullTOC. html, \#2000, 2009.
Siems, S. T., Bretherton, C. S., Baker, M. B., Shy, S. S., and Breidenthal, R. E.: Buoyancy reversal and cloud-top entrainment instability. Q. Q. J. Roy. Meteorol. Soc., 116, 705-739, 1990.

Stevens, B., Moeng, C. H., Ackerman, A. S., Bretherton, C. S. Chlond, A., de Roode, S., Edwards, J., Golaz, J. C., Jiang, H., Khairoutdinov, M., Kirkpatrick, M. P., Lewellen, D. C., Lock, A., Müller, F., Stevens, D. E., Whelan, E., and Zhu P.: Evaluation of Large-Eddy Simulations via Observations of Nocturnal Marine Stratocumulus, Mon. Weather Rev., 133, 1443-1462, 2005.

Sundqvist, H., Berge, E., and Kristjansson, J. E.: Condensation and cloud studies with mesoscale numerical weather prediction model, Mon. Weather Rev., 117, 1641-1757, 1989.

Tiedtke, M.: The sensitivity of the time-mean large-scale flow to cumulus convection in the ECMWF model, ECMWF Workshop on Convection in Large-Scale Models, 28 November-1 December 1983, Reading, UK, 297-316, 1983.

Troen, I. and Mahrt, L.: A simple model of the atmospheric boundary layer; Sensitivity to surface evaporation. Bound.-Layer Meteorol., 37, 129-148, 1986.

Wang, W., Saha, S., Pan, H.-L., Nadiga, S., and White, G.: Simulation of ENSO in the new NCEP coupled forecast system model (CFS03), Mon. Weather Rev., 133, 1574-1593, 2005.

Wang, Y., Xu, H., and Xie, S. P.: Regional model simulations of marine boundary layer clouds over the southeast Pacific off South America. Part II: sensitivity experiments, Mon. Weather Rev., 132, 2650-2668, 2004.

Wang, Y., Xie, S.-P., Wang, B., and Xu, H.: Large-scale atmospheric forcing by Southeast Pacific boundary-layer clouds: A regional model study, J. Climate, 18, 934-951, 2005.

Xiao, H., Wu, C.-M., and Mechoso, C. R.: Buoyancy reversal, decoupling and the transition from stratocumulus-topped to trade cumulus-topped marine boundary layers, Clim. Dynam., doi:10.1007/s00382-010-0882-3, 2010.

Xie, P. and Arkin, P. A.: Global precipitation: a 17-year monthly analysis based on gauge observation, satellite estimates, and numerical model outputs. Mon. Weather Rev., 78, 2539-2558, 1997.

Xu, K. M., and Randall, D. A.: A semiemperical cloudiness parameterization for use in climate models, J. Atmos. Sci., 53, 3084 3102, 1996.

Zhao, Q. Y. and Carr, F. H.: A prognostic cloud scheme for operational NWP models, Mon. Weather Rev., 125, 1931-1953, 1997. 